\title{
Climatological Drought Analyses and Projection Using SPI and PDSI: Case Study of the Arkansas Red River Basin
}

\author{
Lu Liu'; Yang Hong ${ }^{2}$; Jonathan Looper ${ }^{3} ;$ Rachel Riley4; Bin Yong ${ }^{5}$; \\ Zengxin Zhang ${ }^{6}$; James Hocker ${ }^{7}$; and Mark Shafer ${ }^{8}$
}

\begin{abstract}
This paper examines past drought and assesses future drought scenarios for the Arkansas Red River Basin using two common drought indexes, the Standardized Precipitation Index (SPI) and Palmer Drought Severity Index (PDSI). Historical climate data within the 1900-2009 time frame were used to derive the past drought index estimates. The projected climate data under two greenhouse gas emission scenarios from 16 global climate models (GCMs) after bias correction and statistical downscaling were applied in drought occurrence frequency and affected area projection. The results derived from the SPI and PDSI show that widespread droughts mainly took place in the 1910s, 1930s, 1950s, and 1960s in the Arkansas Red River Basin, which agrees well with the historical climate record. Both the SPI and PDSI project that more frequent and severe droughts will appear in the second part of the 21 st century under both of the emissions scenarios. Future PDSI projects that more severe droughts will occur in the western parts of this basin under one scenario. DOI: 10.1061/(ASCE)HE.19435584.0000619. (C) 2013 American Society of Civil Engineers.
\end{abstract}

CE Database subject headings: Arkansas; River basins; Climate change; Droughts; Case studies.

Author keywords: Arkansas Red River Basin; Drought; Climate change; Projection; Global climate models (GCMs).

\section{Introduction}

Observations from various disciplines of science have gradually proven that the average temperature of the Earth is continuously increasing [Intergovernmental Panel on Climate Change (IPCC) 2007]. Global climate model (GCM) projections also show that the average temperature of the Earth will continue to increase in the next 90 years (Karl et al. 2009). Increasing temperatures will lead to higher evaporation rates, which could limit water supplies. Hence, studies on climate change impacts on water resources (e.g., drought) have consequently become not only scientifically necessary, but also economically and socially valuable (Medina 2010; Zhang et al. 2012). As a water-related climate phenomenon,

${ }^{1}$ School of Civil Engineering and Environmental Science, Univ. of Oklahoma, Norman, OK 73072.

${ }^{2}$ School of Civil Engineering and Environmental Science, Univ. of Oklahoma, 120 David L. Boren Blvd., National Weather Center, Atmosphere Radar Research Center, Suite 4610, Norman, OK 73072 (corresponding author). E-mail: yanghong@ou.edu

${ }^{3}$ School of Civil Engineering and Environmental Science, Univ. of Oklahoma, Norman, OK 73072.

${ }^{4}$ Southern Climate Impacts Planning Program, Oklahoma Climatological Survey, Univ. of Oklahoma, Norman, OK 73072.

${ }^{5}$ State Key Laboratory of Hydrology-Water Resources and Hydraulic Engineering, Hohai Univ., Nanjing 210098, China.

${ }^{6}$ College of Forest Resources and Environment, Nanjing Forestry Univ., Nanjing 210037, China.

${ }^{7}$ Southern Climate Impacts Planning Program, Oklahoma Climatological Survey, Univ. of Oklahoma, Norman, OK 73072.

${ }^{8}$ Southern Climate Impacts Planning Program, Oklahoma Climatological Survey, Univ. of Oklahoma, Norman, OK 73072.

Note. This manuscript was submitted on September 29, 2011; approved on March 23, 2012; published online on June 14, 2013. Discussion period open until December 1, 2013; separate discussions must be submitted for individual papers. This paper is part of the Journal of Hydrologic Engineering, Vol. 18, No. 7, July 1, 2013. (C) ASCE, ISSN 1084-0699/2013/7809-816/\$25.00. drought is a devastating climate-related hazard with recurrent features. It occurs virtually in all climate zones and impacts the natural ecological system and society (National Drought Mitigation Center 2006). Knowing when and where a drought might take place and how severe it might become under future climate scenarios is essential for a resilient society both in terms of economic well-being and development.

Drought is difficult to define, although common definitions consider drought as a deficiency of precipitation over an extended period of time, resulting in a water shortage for some activity, group, or environmental sector (Landsberg 1982). Because drought is covered under a plethora of different scientific categories, scientists place this phenomenon into four different classifications: meteorological drought, agricultural drought, hydrological drought, and socioeconomic drought (National Drought Mitigation Center 2006). Meteorological drought is simply the departure from normal of meteorological variables that induces drying of the surface. It is usually region-specific because the atmospheric conditions in different areas are highly variable in space and time. Agricultural drought considers whether the water quantity in soil meets the demand of plants at various growing stages. It will occur when the soil moisture fails to nourish the plants. This could result from a meteorological drought, which is caused by a lack of rainfall, or from a hydrological drought, which is indicated by the dropping groundwater level. Hydrological drought is often based on reservoirs or lake levels. It is a basin-scale drought, which could be initially caused by rainfall deficits. Therefore, a latent effect to meteorological drought could be observed in a hydrological drought. Socioeconomic drought results from a demandsupply issue concerning water usage and water-related industries. If the water supply fails to meet the demand of its users, a socioeconomic drought will probably occur (National Drought Mitigation Center 2006).

The region used for this study was the Arkansas Red River Basin (ABRFC) (http://www.srh.noaa.gov/abrfc/), which includes parts of seven states in and around Oklahoma and covers approximately 


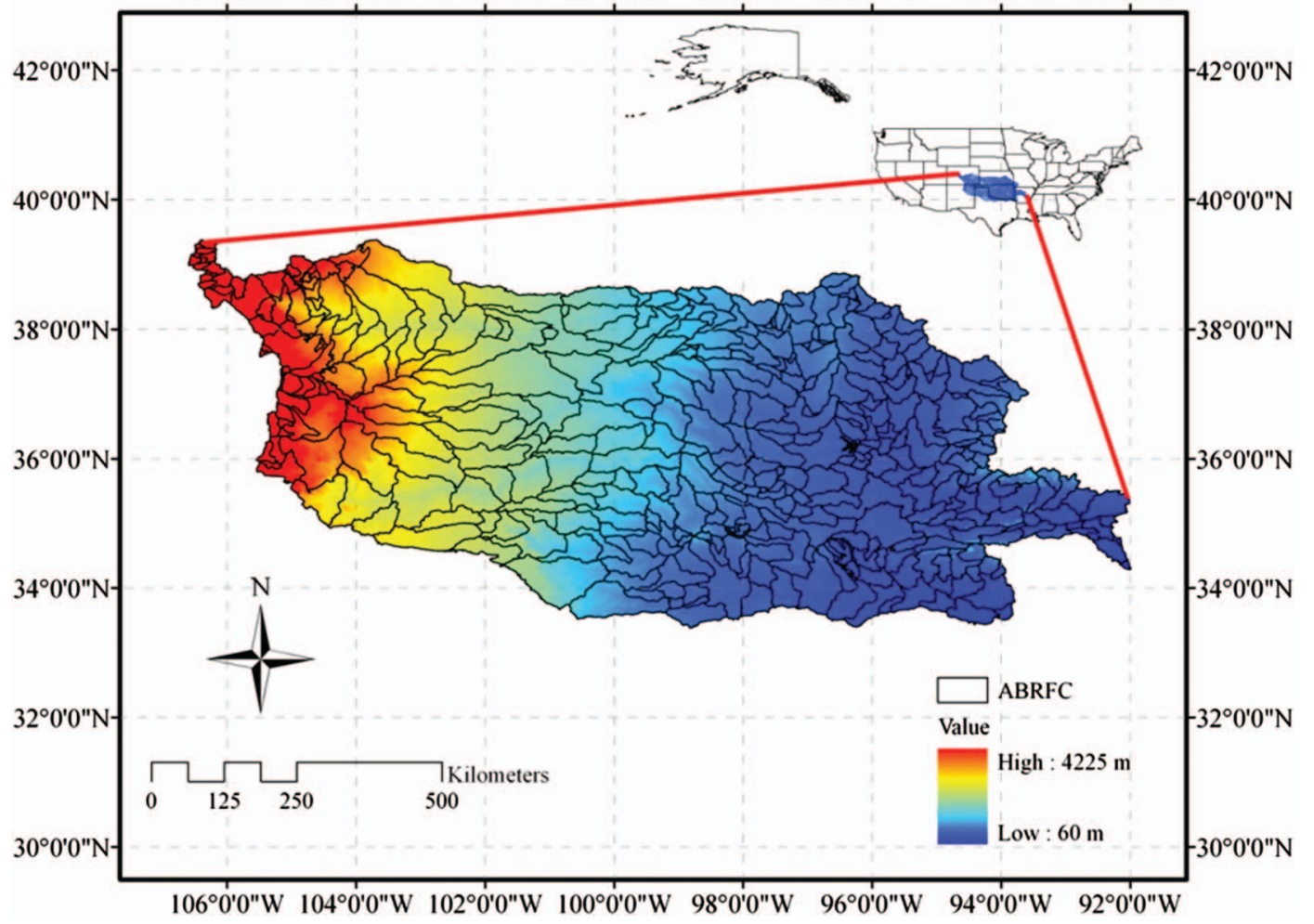

Fig. 1. (Color) Study region: Arkansas-Red River Basin with topography [base map from the Arkansas-Red Basin River Forecast Center (ABRFC) (http://www.srh.noaa.gov/abrfc/)]

$540,000 \mathrm{~km}^{2}$ (Fig. 1). The major aquifers within the ABRFC, such as the part of the Ogallala Aquifer, are the main water sources for agriculture and municipal water usage for the states. Major cities within the ABRFC area include Colorado Springs, Colorado; Dodge City and Wichita, Kansas; Oklahoma City; and Amarillo, Texas, among others. It is very important to study the water availability issues in the ABRFC from different perspectives because millions of U.S. citizens rely on water from this region.

Because drought is difficult to quantify, a wealth of drought indexes have been developed to assimilate thousands of bits of data on rainfall, snowpack, streamflow, and other water supply indicators into a comprehensible big picture. The drought indexes used in this study were the Standardized Precipitation Index (SPI) (McKee et al. 1993) and the Palmer Drought Severity Index (PDSI) (Palmer 1965). Detailed discussions of the two indexes are included in the following section.

Understanding the characteristics of historical droughts will reveal some possible effects of future droughts under a changing climate (Edwards and McKee 1997). Therefore, to fill current research gaps in this area, it is necessary to reconstruct past drought situations and assess future drought risks for the drought-prone ABRFC under a likely changing climate given that such evaluation plays an important role in regional water management. The main objective of this research is to analyze past droughts in the ABRFC and identify how projected climate changes affect the intensity, duration, and extent of future droughts.

\section{Data and Drought Indexes}

\section{Data}

The monthly precipitation and temperature data of the region were extracted in order to calculate the SPI and PDSI drought indexes.
The observational data used for this study were the gridded National Climatic Data Center (NCDC) Cooperative Observer Program (COOP) station data (Maurer et al. 2002) (http://hydro.engr .scu.edu/files/gridded_obs/monthly/ncfiles_2010/). The data covers the time period from 1950 to 1999 in a monthly time step and contains surface temperature $\left({ }^{\circ} \mathrm{C}\right)$ and monthly precipitation readings. The NCDC COOP domain covers the continental United States and portions of southern Canada along with northern Mexico at a $1 / 8^{\circ}(\sim 12-\mathrm{km})$ resolution.

Another historical data set that was used was the ParameterElevation Regressions on Independent Slopes Model (PRISM) developed by Oregon State University (http://www.prism.oregonstate .edu/index.phtml). This 4-km resolution data set covers the United States from 1900 to 2009 in a monthly time step. Only precipitation data are available for archive at this phase, although PRISM data were archived in this study for comparison with the observations provided, and they is also used to simulate drought conditions prior to 1950.

Projection data were derived from the World Climate Research Programme's (WCRP's) Coupled Model Intercomparison Project Phase 3 (CMIP3) multimodel data set (http://gdo-dcp.ucllnl .org/downscaled_cmip3_projections/dcpInterface.html\#Projections: $\% 20$ Complete\%20Archives). CMIP3 has temperature and precipitation projections by three greenhouse gas emission scenarios from 2000 to 2099 and these data have the same resolution and coverage with NCDC observation data.

The two $\mathrm{CO}_{2}$ emission scenarios used in this study were A2 and $\mathrm{A} 1 \mathrm{~B}$ as defined in the IPCC Special Report on Emissions Scenarios (IPCC 2000). According to the IPCC AR4, scenario A2 is a higher-emission path and describes a more populated world in which technological change and economic growth are more fragmented and slower. Scenario A1B is a middle emission path known as "business-as-usual" and describes a balanced world in 
which people do not rely too heavily on any one particular energy source.

\section{Drought Indexes}

\section{Standardized Precipitation Index}

SPI is used to indicate meteorological drought, which is mainly caused by a deficiency of precipitation; it was developed by McKee et al. (1993). The SPI is an index based on the probability of precipitation for any time scale. In McKee et al. (1993), SPI was calculated at 3-, 6-, 12-, 24-, and 48-month time scales based on Fort Collins, Colorado, precipitation data. Then long-term precipitation data were fit into a probability distribution, which was then transformed into a standard distribution. Therefore, the regionspecific deviation from the data is largely eliminated. Zero means normal conditions, while positive and negative values are indicating wet and dry conditions. The index of SPI can provide early warnings to help assess drought severity. But it is only derived from the meteorological element of precipitation without considering other important parameters for the description of drought, such as evapotranspiration or soil moisture. Therefore, a more comprehensive index should also be used to serve as a comparison.

\section{Palmer Drought Severity Index}

The Palmer Drought Severity Index is an indicator of a hydrometeorological drought that has been used for the last 45 years. Instead of taking only precipitation into account, PDSI also considers temperature, which has a huge impact on evapotranspiration and soil moisture. This index provides a more comprehensive method to assess the effects of climate change on drought because it requires more climate variables as input (Palmer 1965).

The PDSI is an indicator of prolonged soil moisture deficiency (Palmer 1965). While it estimates soil moisture using a simple two-layer soil description, it has been shown to be strongly correlated $(r=0.5-0.7)$ with measured soil moisture (Dai et al. 2004). The PDSI soil parameter used for a bucket water balance is the available water content (AWC). AWC is the difference between the soil moisture at field capacity and the wilting point. For this study, AWC was determined from the State Soil Geographic Database (STATSGO) for the top $100 \mathrm{~cm}$ of the soil profile. The STATSGO soil database has a spatial resolution of $1 \mathrm{~km}$ (Fig. 2).

Eq. (1) illustrates the components of the PDSI calculation; evapotranspiration (ET), recharge $(R)$, runoff (RO), loss $(L)$, potential evapotranspiration (PE), potential recharge (PR), potential runoff (PRO), and potential loss (PL). The deficit in soil moisture, $d_{i}$, measures the difference between precipitation and the required precipitation to maintain the long-term monthly soil moisture (Wells et al. 2004). The software package provided by the University of Nebraska (Wells et al. 2004) calculated the PDSI on a monthly time step.

$$
d_{i}=P-(\alpha \mathrm{PE}+\beta \mathrm{PR}+\gamma \mathrm{PRO}+\delta \mathrm{PL})
$$

where

$$
\begin{aligned}
& \alpha=\frac{E(\mathrm{ET})}{E(\mathrm{PE})} ; \quad \beta=\frac{E(R)}{E(\mathrm{PR})} ; \quad \gamma=\frac{E(\mathrm{RO})}{E(\mathrm{PRO})} ; \\
& \delta=\frac{E(L)}{E(\mathrm{PL})}
\end{aligned}
$$

The next step in the procedure is the climate characteristic value $K$, which helps standardize the index across varying climates. For example, the moisture deficit between the desert and the tropical regions should be identified and found comparable. Palmer defined $K$ to relate the average moisture supply to the average moisture deficits.

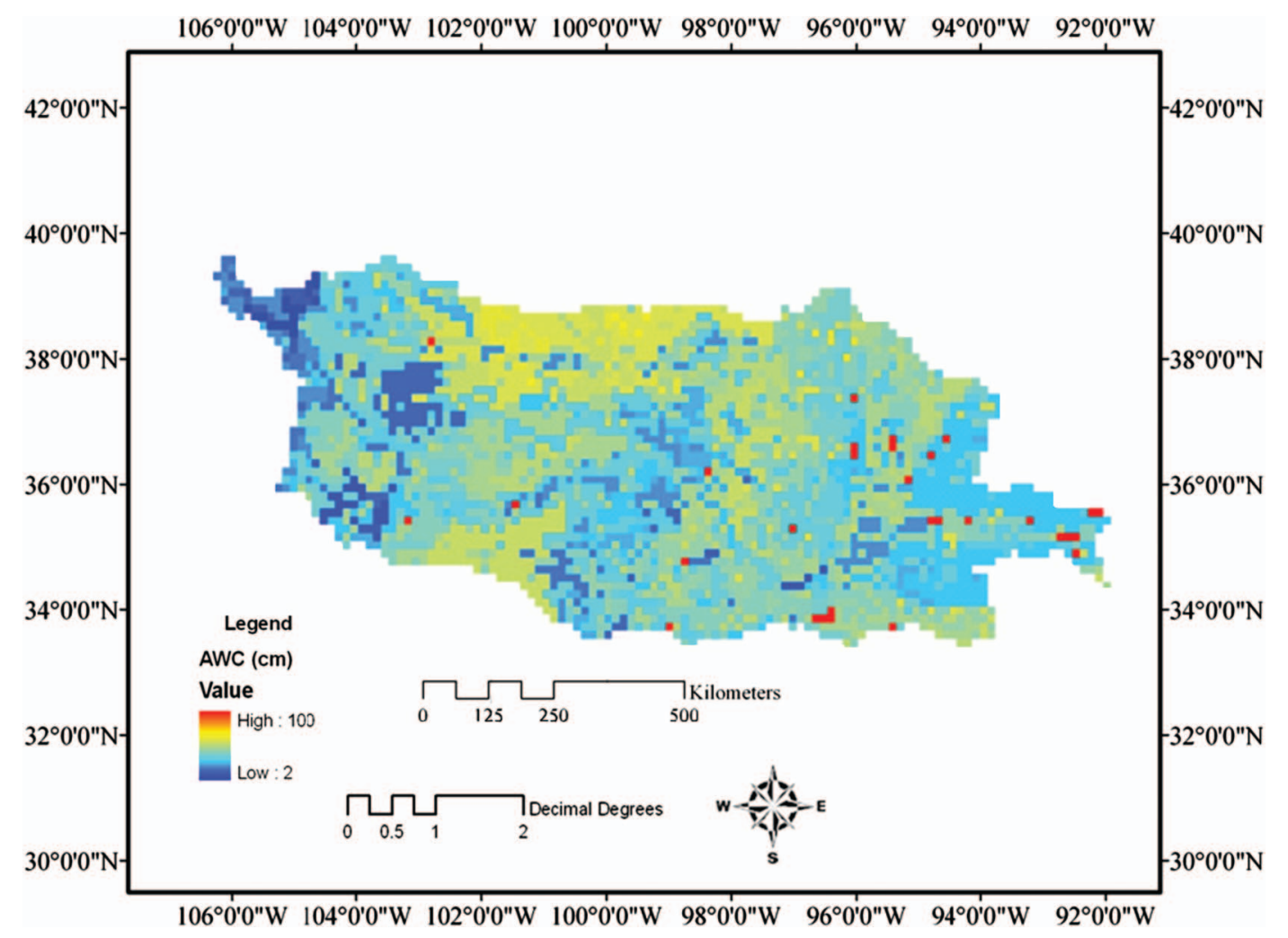

Fig. 2. (Color) AWC distribution over ABRFC 


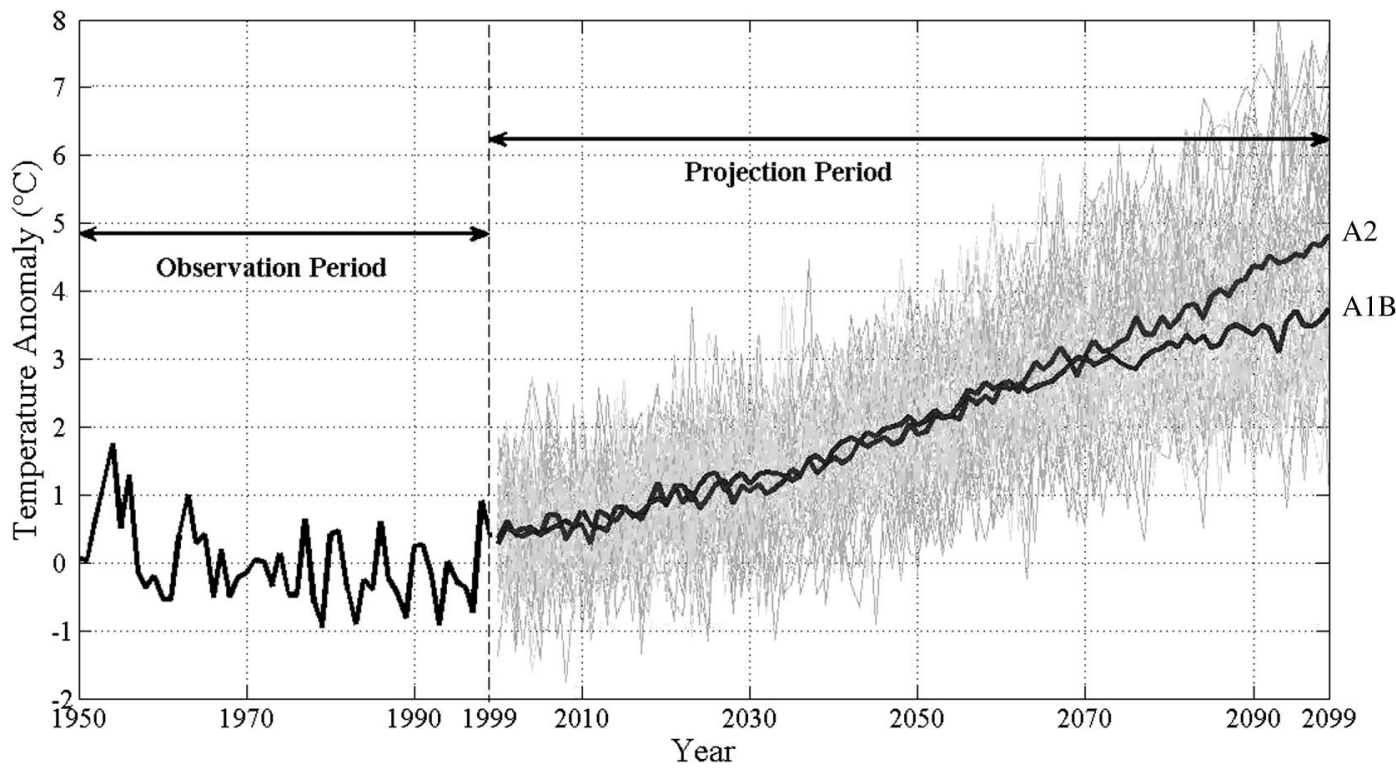

Fig. 3. Temperature anomaly over ABRFC for the period 2000 to 2099 compared with 1950 to 1999 mean under A2 and A1B emission scenario; the light lines are each individual members in the 16 GCMs; the bold lines are the ensemble means from 16 GCMs

$K_{i}=\left(\frac{17.6}{\sum_{i=1}^{12} \bar{D}_{i} K_{i}^{\prime}}\right)\left(1.5 \log _{10}\left\{\frac{\left[\frac{E(\mathrm{PE})+E(R)+E(\mathrm{RO})}{E(P)+E(L)}+2.8\right]}{E(D)}\right\}+0.5\right)$

The climate characteristic, $K$, and deficit, $d$, are then combined to form the moisture anomaly index, $Z$. This indicator is

$$
Z=K d
$$

Finally, PDSI is computed using Eq. (4).

$$
\operatorname{PDSI}_{i}=0.897 \mathrm{PDSI}_{i=1}+\frac{1}{3} Z_{i}
$$

Zero means normal conditions, while positive and negative values are indicating wet and dry conditions. The coefficients
0.897 and $1 / 3$ include the effects of time on drought predictions. The weighting gives more importance to the previous month's PDSI over short-term precipitation events that can increase $Z_{i}$.

\section{Results}

\section{Past and Future Climate}

The temperature and precipitation change anomalies over ABRFC in a yearly time step are shown in Figs. 3 and 4. There is a decreasing temperature trend from 1950 to 1975 with a peak around 1955 (Fig. 3). The temperature increases slightly after 1975 and the trend continues from 2010 until 2099, during which the average temperature over the $\mathrm{ABRFC}$ increases almost $4^{\circ} \mathrm{C}$ under the $\mathrm{A} 1 \mathrm{~B}$ scenario and $5^{\circ} \mathrm{C}$ under $\mathrm{A} 2$. The results show that climate change

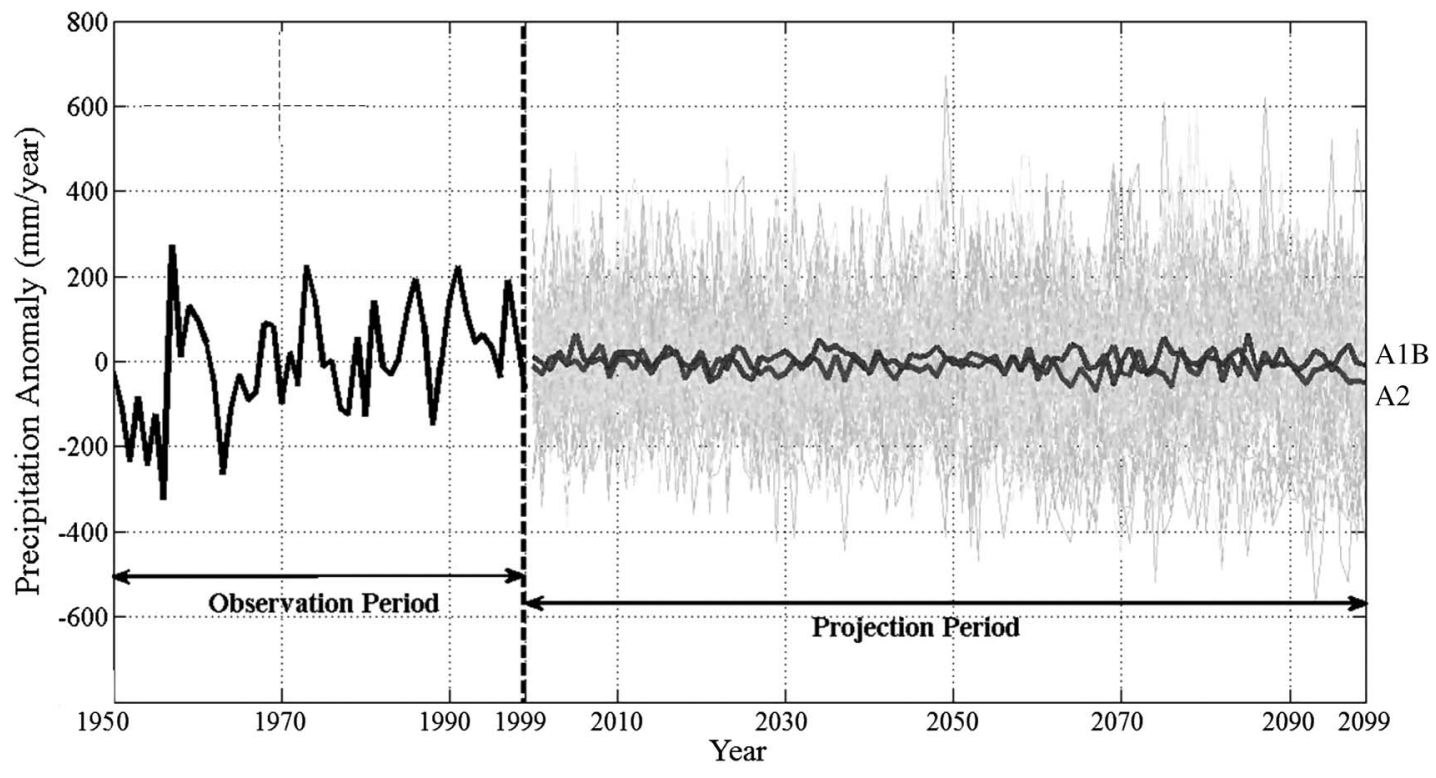

Fig. 4. Precipitation anomaly over ABRFC for the period 2010 to 2099 compared with 1950 to 1999 mean under A2 and A1B emission scenario; the light lines are each individual members in the 16 GCMs; the bold lines are the ensemble means from 16 GCMs 
(regional warming specifically) became substantial since 1975. The trend continues throughout the 21 st century.

The precipitation trends show more variability for the past 50 years (Fig. 4). The least amount of rain fell around 1955, but the most occurred around 1960. However, the overall precipitation trend for the period was a slight increase. Although the trend does not appear obvious for the period of 2010-2099 mainly because the projection is the ensemble mean of $16 \mathrm{GCMs}$, there are

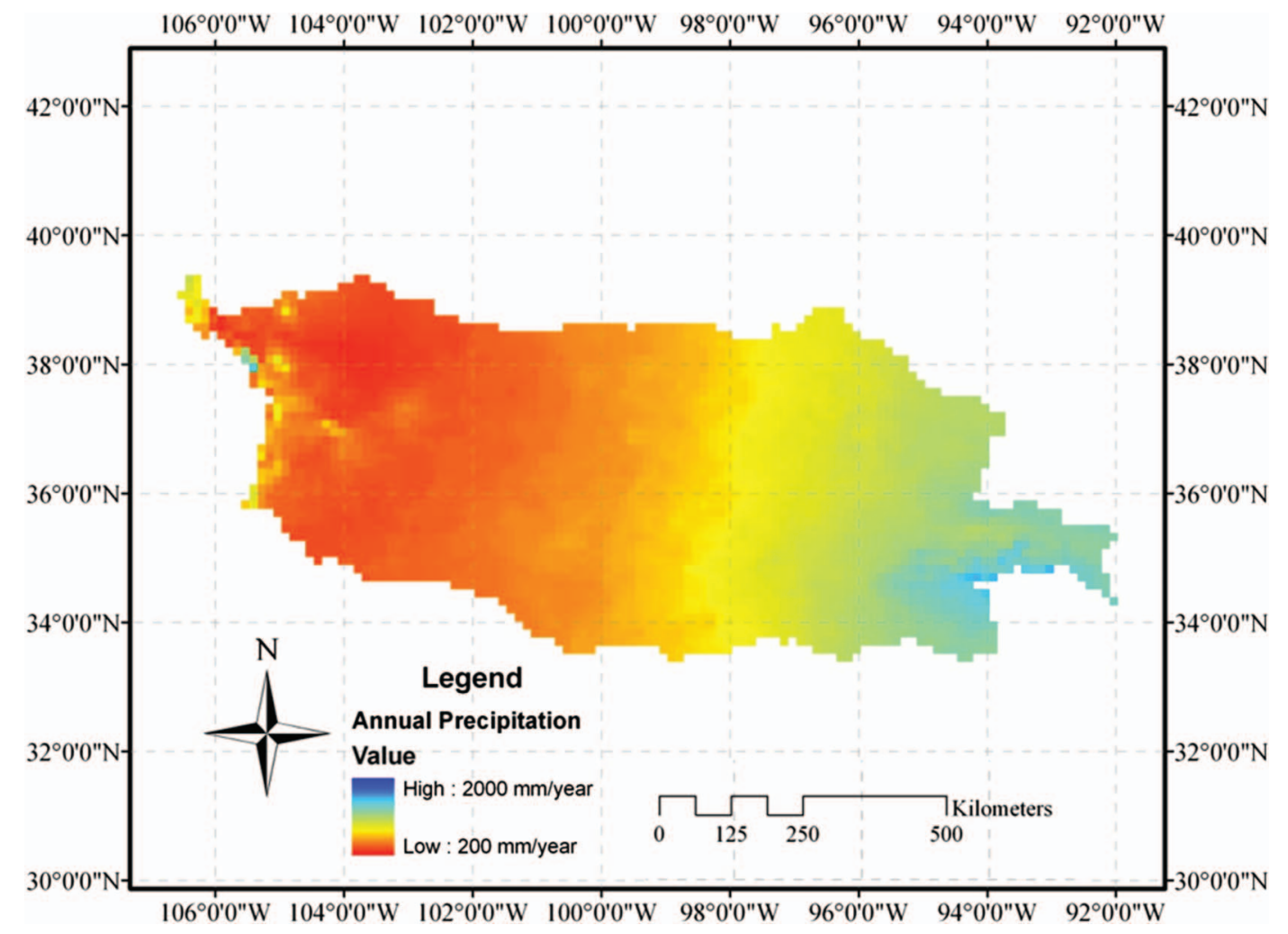

Fig. 5. (Color) Annual precipitation distribution over ABRFC for the period of 1950 to 1999
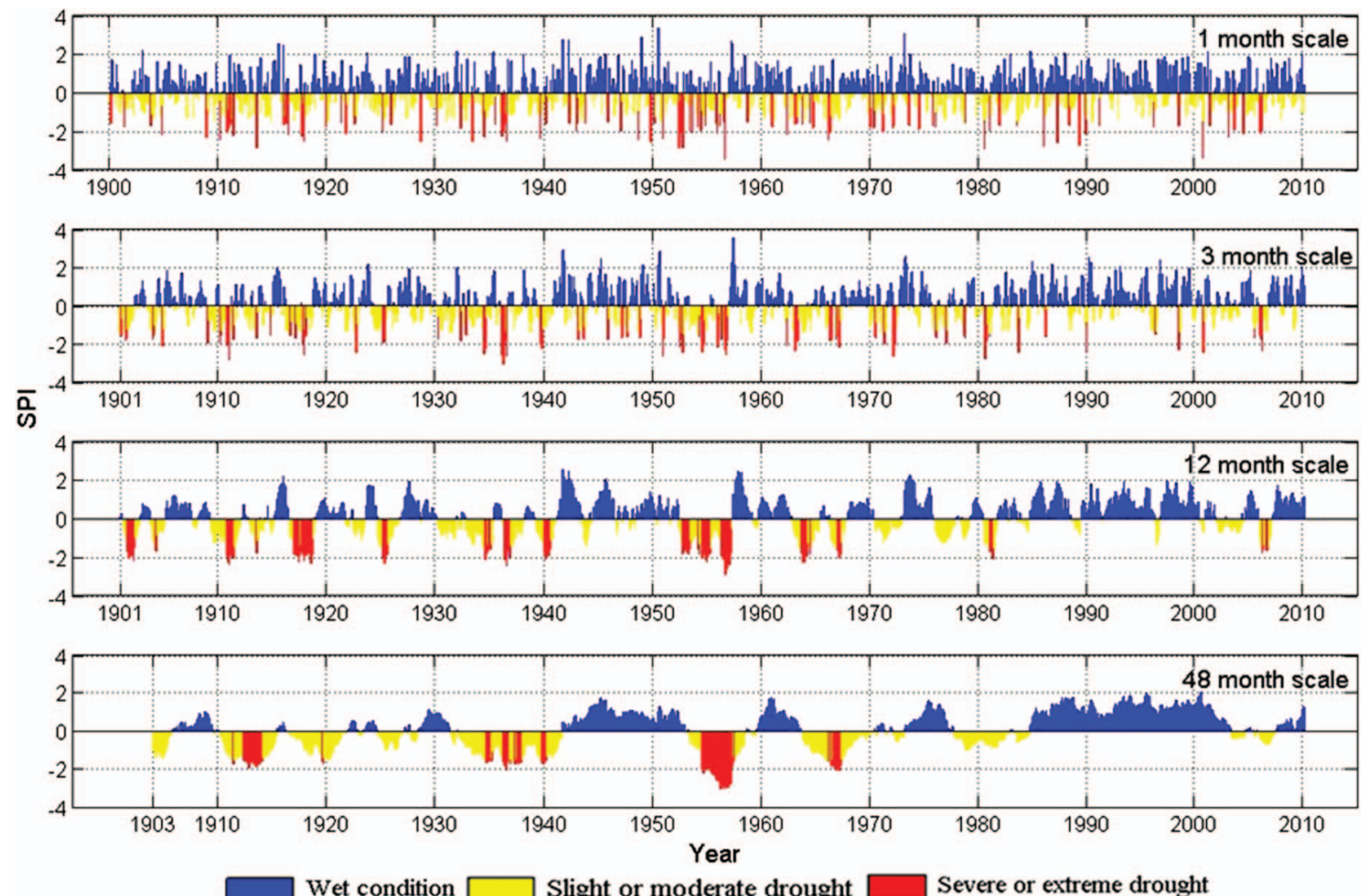

Wet condition

Slight or moderate drought

Severe or extreme drought

Fig. 6. (Color) SPI over ABRFC for the period of 1900-2000 for 1-, 3-, 12-, and 48-month scales 

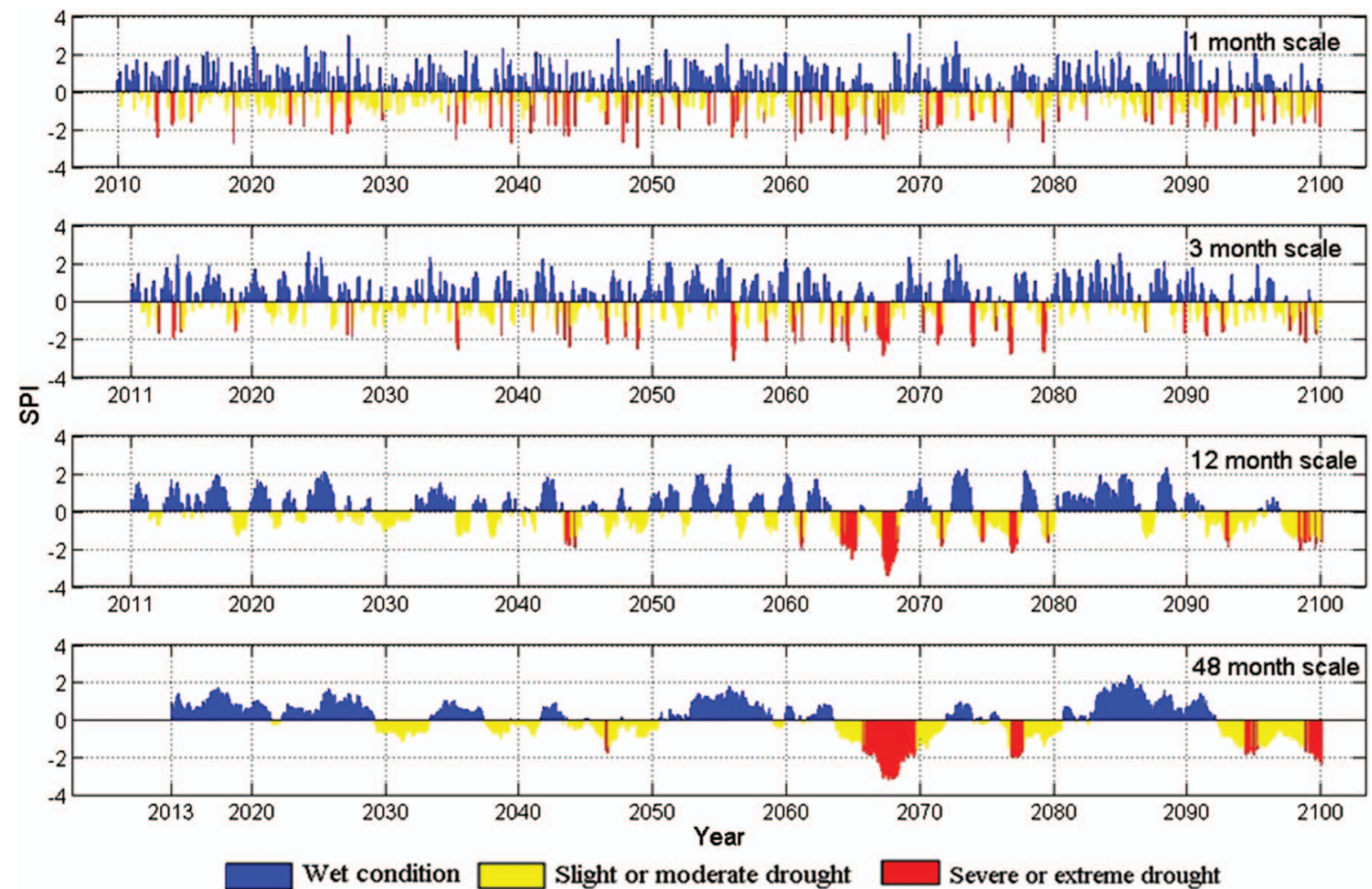

Fig. 7. (Color) SPI over ABRFC for the period of 2010-2099 for 1-, 3-, 12-, and 48-month scales under A2 emission scenario

large variations among different GCMs. Still, the ensemble mean of GCMs under A2 shows a slight decreasing trend after 2050.

The spatial pattern of precipitation distribution from 1950-1999 is shown in Fig. 5. There is a large gradient between northwestern portions of the ABRFC and southeastern ABRFC, with the northwestern regions receiving approximately $300 \mathrm{~mm} /$ year of rainfall and southeastern areas getting more than $1,000 \mathrm{~mm} /$ year. It appears that the precipitation pattern around the Rocky Mountains displays certain abnormal behavior, which could be explained by the fact that statistical downscaling methods have some difficulties resolving mountainous rainfall characteristics.

\section{SPI Results}

The SPI results for 1900-2009 based on PRISM data are shown in Fig. 6. In this study, 1-, 3-, 12-, and 48-month scales are studied to assess the intensity and duration of the major droughts in the ABRFC region. As can be seen from Fig. 5 for the 48-month panel, four major droughts took place in the 1910s, 1930s, 1950s, and 1960s. The most serious one was the 1950s drought, which lasted for almost half a decade. The 1930s drought consists of several intensive individual droughts with shorter durations. Historical records show that Oklahoma experienced four major droughts in the twentieth century: 1909-1918, 1930-1940, 1952-1956, and 2001-2002. While the drought of the 1930s is historically associated with the Dust Bowl of the Great Plains, statistics show that the drought of the 1950s was more severe for Oklahoma as indicated by record low SPI and PDSI values (Arndt 2002). However, socioeconomic effects were less severe because Oklahoma's population learned to cope with the Dust Bowl and put into place agricultural and water management practices that mitigated many of the worst effects of the Dust Bowl. The duration of the recent 2001-2002 drought was only a few months, therefore it was not shown on the 12- and 48-month scale. The 1-month scale panel does however, display this shorter-duration drought. The length of the red bar around 2001 indicates that the drought is quite severe, yet it does not last long enough to be displayed on the 12- or 48-month scale panel. These results indicate that SPI is able to capture the major droughts in the ABRFC for the past half century.

SPI projection for the A2 scenario at the 1-, 3-, 12-, and 48-month scales is shown in Fig. 7. The 48-month scale panel displays a severe drought in the late 2060s, which lasts almost half a decade. This drought event has similar temporal patterns as the one in the 1950s. Identically, the 2060s drought is followed by a shorter-duration 2070s drought, which also resembles the 1960 s drought following the 1950 s one.

\section{PDSI Results}

The input data for computing PDSI are temperature and precipitation, and therefore PDSI is only computed from 1950 to 1999 because PRISM does not provide temperature data. Fig. 8 shows

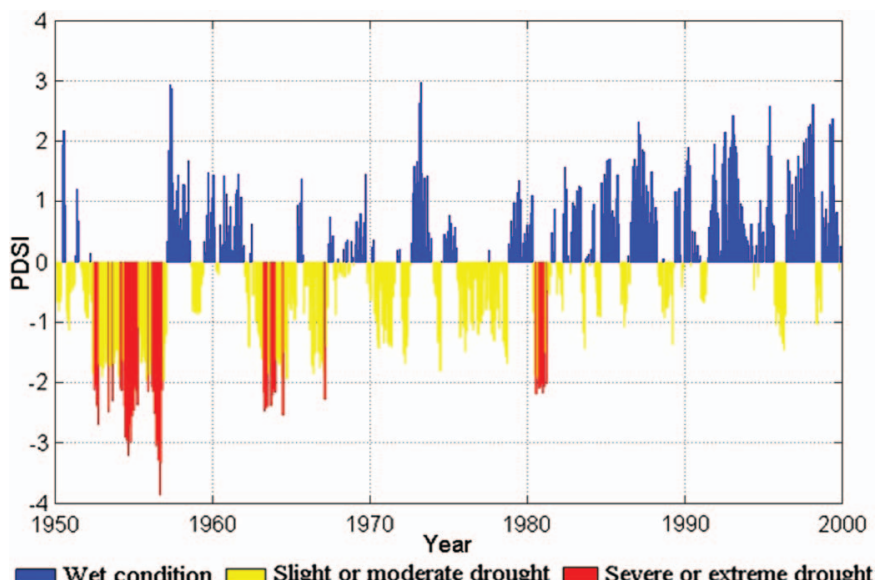

Fig. 8. (Color) PDSI over ABRFC for the period of 1950 to 1999 

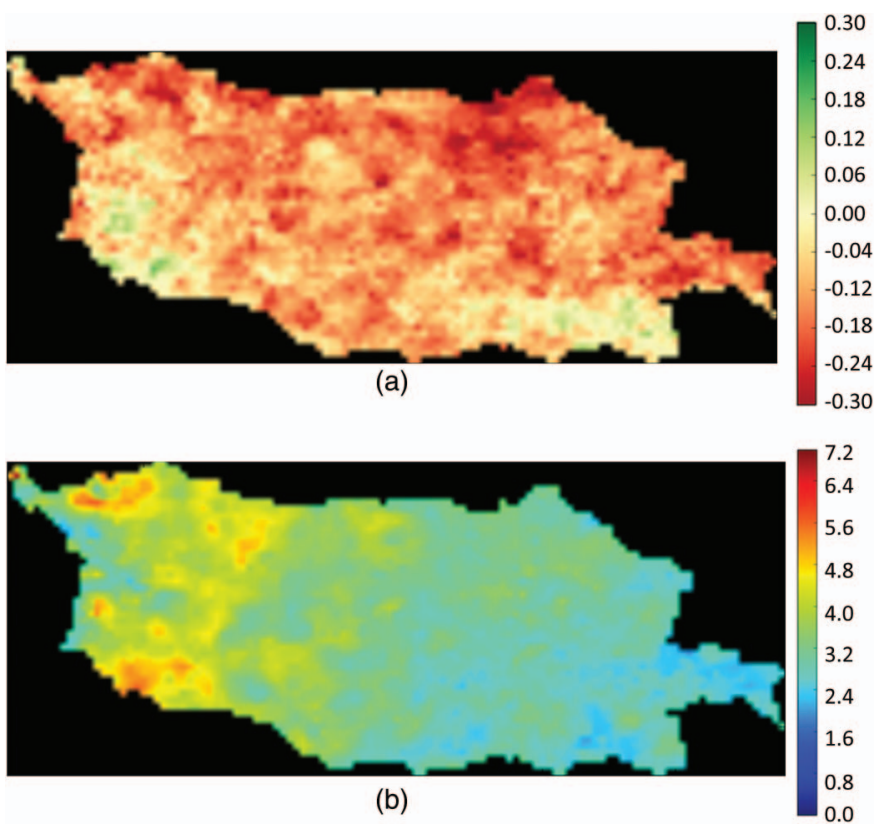

Fig. 9. (Color) (a) Mean PDSI distribution over ABRFC for the period of 1950 to 1999; (b) variance of PDSI distribution over ABRFC for the period of 1950 to 1999

the temporal pattern of PDSI from 1950-1999. Similarly, PDSI also captures the major droughts of the 1950s, 1960s, and 1980s. There has been a trend toward wetter conditions since the mid-1950s. There also was an increase in the variance of PDSI after 1980. Fig. 9 shows the spatial mean and variance of PDSI for 1950-1999. The mean PDSI is -0.12 for the entire ABRFC region over this 50 -year period. This indicates that the area experienced minor drought conditions during the period. However, the 1-month-scale PDSI showed large variability in all the grids, with the minimum and maximum values -8.6 and +11.5 , respectively, indicating that many local locations within the basin experienced severe dry and wet spells over the 50-year period. The variance of PDSI showed that the western portions of the ABRFC region experienced larger temporal and spatial variability of drought during the 1950-1999 period. This corresponds with the areas that received much less mean precipitation but with higher variations.

The projected PDSI for the future period was determined under the more realistic A1B scenario using ensemble means for precipitation and temperature. The study looks at the mean PDSI in 30-year increments for the periods of 2010-2039, 2040-2069, and 2070-2099 (Fig. 10). There appears to be a wetter period during the 2010-2039 time frame, predominantly in the western regions (Texas and Colorado) of the ABRFC. During the period of 2070 to 2099, this same region experiences a more severe drought than the eastern region. This same area saw a higher variance during the period of 1950 to 1999 . This shows that climate change is likely to contribute to drought in the western region of ABRFC, which generally receives less precipitation than its eastern counterpart (Fig. 5).

Fig. 11 displays the probability distribution functions (PDFs) of PDSI for the near future (2010-2039), midfuture (2040-2069), and far future (2070-2099) under the A1B scenario. Although the ABRFC is expected to experience wetness in the near future, the overall trend goes toward dryness over time. The midfuture is expected to become drier than the near future, and the drought condition becomes worst in the far future. PDSI moves toward lower

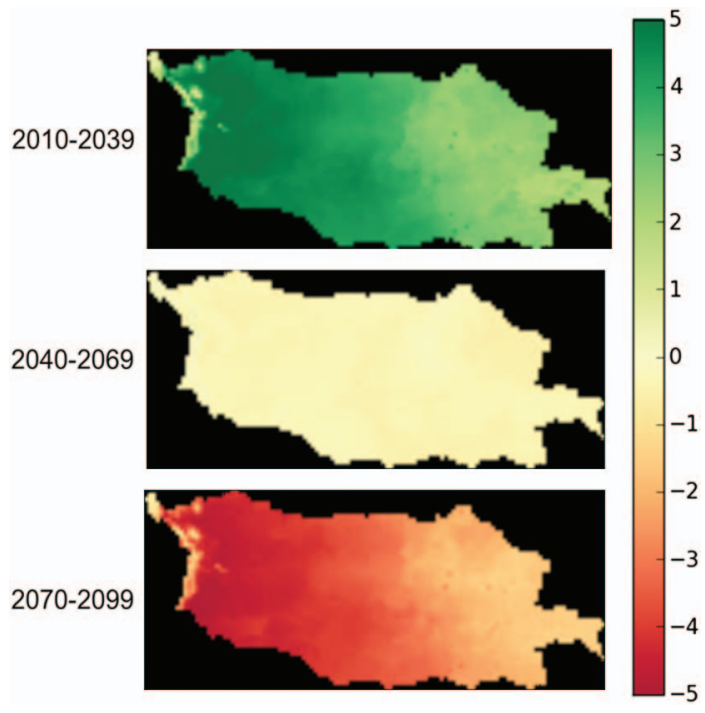

Fig. 10. (Color) PDSI anomaly distribution over ABRFC for the period of 2010 to 2099 compared with 1950 to 1999 mean under A1B emission scenario

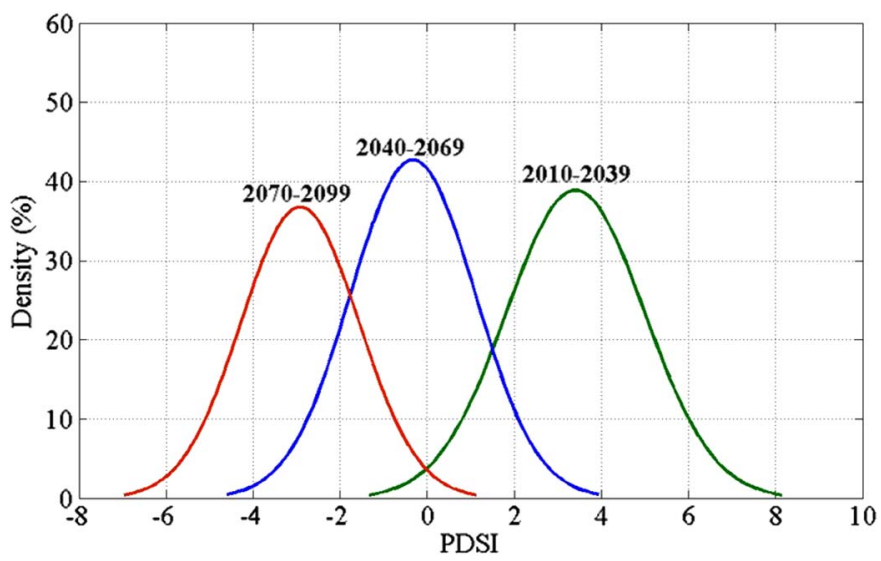

Fig. 11. PDFs of PDSI for the period of 2010-2039, 2040-2069, and 2070-2099 under the A1B emission scenario

extreme values during the 2040-2099 year period, which indicates that future drought is likely to get more severe and frequent. The same result was also projected by the SPI.

\section{Conclusions and Discussions}

The temperature in the $\mathrm{ABRFC}$ region is projected to increase after 2010 , and it is projected to increase by $3-5^{\circ} \mathrm{C}$, depending on the climate scenarios, by the end of this century. There is no discernible trend in the ensemble mean of precipitation projections, however, except that A2 shows a slight decreasing trend after the 2050s.

Both the SPI and PDSI capture the major drought characteristics that happened in ABRFC during the past century. The two indicators reconcile quite well from 1950 to 1999 , but show some differences in the future. The reasons might be that (1) the temperature change before 2000 is not as much as that after 2010; in this case, PDSI is not as affected as much by the temperature factor as it is for the period after 2010 in which higher evapotranspiration induced by warming temperature leads to decreasing PDSI values; or (2) the 
slightly decreasing SPI values, which only considers the meteorological element of precipitation, are mainly due to the decreasing precipitation trend from the $16 \mathrm{GCMs}$ projected by the A2 scenario. Therefore, SPI is only able to provide future drought assessment from a pure meteorological perspective, the precipitation in particular.

According to the SPI, ABRFC experiences relatively wet conditions during the first half of the 21st century, but precipitation gets less abundant after 2060, which leads to a severe drought in the mid late 2060s, followed by another severe drought in the late 2070s. This indicates a possible drought cycle of 110 years, taking the drought occurrences throughout the twentieth and 21 st centuries into consideration.

According to the PDSI, it appears that overall this region is going to get drier and the western portions of the ABRFC region will experience a more severe drought than the eastern portions during the second half of the 21 st century. Additionally, the simulation still indicates that a wetter period will occur from 2010 to 2039. These simulations also imply that a greater strain will be put on the groundwater and surface water resources during the second half of the century.

\section{Acknowledgments}

This research is funded by the Southern Climate Information Planning Program (SCIPP) (http://www.southernclimate.org). The authors thank the National Weather Center for their computing resources and also acknowledge their colleagues within the Hydrometeorology and Remote Sensing Laboratory (http://hydro.ou.edu) for their technical support. In addition, the authors acknowledge the modeling groups, the Program for Climate Model Diagnosis and Intercomparison (PCMDI), and the WCRP's Working Group on Coupled Modeling (WGCM) for their roles in making available the WCRP CMIP3 multimodel data sets. Support of these data sets is provided by the Office of Science, U.S. Department of Energy. Also, the authors acknowledge the PRISM Climate Group for providing PRISM precipitation data.

\section{References}

Arndt, D. S. (2002). "The Oklahoma drought of 2001-2002." Oklahoma Event Summary, Oklahoma Climatological Survey, Norman, OK.

Dai, A., Trenberth, K. E., and Qian, T. (2004). "A global data set of Palmer Drought Severity Index for 1870-2002: Relationship with soil moisture and effects of surface warming." J. Hydrometeorol., 5(6), 1117-1130.

Edwards, D. C., and McKee, T. B. (1997). "Characteristics of 20th century drought in the United States at multiple time scales." Climatology Rep. Number 97-2, Colorado State Univ., Fort Collins, CO.

Intergovernmental Panel on Climate Change (IPCC). (2000). Special report on emissions scenarios: A special report of Working Group III of the Intergovernmental Panel on Climate Change, Cambridge University Press, Cambridge, UK.

Intergovernmental Panel on Climate Change (IPCC). (2007). "Climate change 2007: The physical science basis." Contribution of Working Group I to the Fourth Assessment Rep. of the Intergovernmental Panel on Climate Change, Solomon, S., et al., eds., Cambridge University Press, Cambridge, UK.

Karl, T. R., Melillo, J. M., and Peterson, T. C., eds., (2009). Global climate change impacts in the United States: A state of knowledge report from the U.S. Global Change Research Program, Cambridge University Press, New York.

Landsberg, H. E. (1982). "Climatic aspects of drought." Bull. Am. Meteorol. Soc., 63(6), 593-596.

Maurer, E. P., Wood, A. W., Adam, J. C., Lettenmaier, D. P., and Nijssen, B. (2002). "A long-term hydrologically-based data set of land surface fluxes and states for the conterminous United States." J. Clim., 15(22), 3237-3251.

McKee, T. B., Doesken, N. J., and Kleist, J. (1993). "The relationship of drought frequency and duration to time scales." 8th Conf. on Applied Climatology, Anaheim, CA, 179-184.

Medina, M., Jr. (2010). "Global water crisis and climate change." J. Hydrol. Eng., 15(3), 167-170.

National Drought Mitigation Center. (2006). 〈http://drought.unl.edu/ DroughtBasics/TypesofDrought.aspx〉 (Jul. 30, 2011).

Palmer, W. C. (1965). "Meteorological drought." Research Paper No. 45, U.S. Weather Bureau, Washington, DC.

Wells, N., Goddard, S. (2004). "A self-calibrating Palmer Drought Severity Index." J. Clim., 17(12), 2335-2351.

Zhang, J., et al. (2012). "Using hydrologic simulation to explore the impacts of climate change on runoff in the Huaihe River Basin of China." J. Hydrol. Eng., 10.1061/(ASCE)HE.1943-5584.0000581. 